\title{
KAJIAN KARAKTERISTIK ALIRAN TERHADAP BANGUNAN PELIMPAH PADA SALURAN TERBUKA
}

\author{
Syam Sunniati Saleh" ${ }^{1)}$ Ratna Musa ${ }^{2)}$, Hanafi As'ad ${ }^{\text {3) }}$ \\ ${ }^{1)}$ Universitas Muhammadiyah Makassar, Indonesia. \\ Email : uniecivil09@gmail.com \\ ${ }^{2)}$ Universitas Muslim Indonesia, Indonesia \\ Email :ratna_musa@gmail.com \\ 3) Universitas Muslim Indonesia, Indonesia \\ Email :hanafiasad@gmail.com
}

\begin{abstract}
ABSTRAK
Pelimpah (Spillway) merupakan salah satu bangunan pelengkap dari bendungan yang berfungsi sebagai pengaman terhadap bahaya air banjir yang melimpas diatas bendungan (overtopping). Selain itu, bangunan pelimpah juga berfungsi agar debit hujan rancangan yang terjadi cepat mengalir sehingga debit air tidak sempat meluas. Karakteristik aliran yang melewati bangunan pelimpah akan tergantung kepada bentuk dan sifat pelimpah itu sendiri. Untuk kepentingan bangunan air seperti bendungan dan bangunan air lainnya maka perihal karakteristik aliran sangatlah penting untuk menentukan bangunan yang akan dipilih sesuai kebutuhannya. Pengkajian tentang hal ini dapat dilakukan melalui suatu penelitian terhadap aliran pada saluran terbuka berukuran kecil yang melewati pelimpah dengan model bangunan pelimpah type ogee. Adapun tujuan dari penelitian ini yaitu untuk mengetahui karakteristik aliran, pola aliran dan energy spesifik yang terjadi pada bangunan tersebut. Pada penelitian ini dapat disimpulkan bahwa aliran air dapat mengalami perubahan ketinggian karena adanya bangunan pelimpah dan berpengaruh pada karakteristik alirannya. Dimana semakin tinggi muka air maka semakin besar kecepatan yang terjadi.Pola aliran pada daerah hulu merupakan aliran sub kritis $(F R<1)$ kemudian menjadi kritis $(F R=1)$ pada saat melewati bangunan pelimpah. Setelah melewati bangunan pelimpah maka aliran menjadi super kritis (FR > 1) dan berangsur-angsur menjadi normal kembali pada saat berada di daerah hilir.Energi spesifik yang dihasilkan pada bangunan pelimpah tipe Ogee juga bergantung pada jenis pelimpah yang diberikan.
\end{abstract}

Kata Kunci : Pelimpah tipe ogee, Karakteristik Aliran, Energi Spesifik

\begin{abstract}
Spillway is one of the complementary buildings of a dam that serves as a safety against flood water hazards that overflow (overtopping). In addition, the overflow building also functions so that the design rain discharge that occurs quickly flows so that the water discharge does not have time to expand. The flow characteristics that pass through the overflow building will depend on the shape and nature of the overflow itself. For the benefit of water structures such as dams and other water structures, the characteristics of the flow are very important to determine the building to be chosen according to their needs. An assessment of this can be done through a study of the flow in a small open channel that passes through the overflow with the ogee type spillway model. The purpose of this study is to determine the characteristics of flow, flow patterns and specific energy that occurs in the building. In this study it can be concluded that the flow of water can experience changes in altitude due to the presence of overflow buildings and affect the flow characteristics. Where the higher the water level, the greater the speed that occurs. The flow pattern in the upstream area is a sub-critical flow $(F R<1)$ then becomes critical $(F R=$ 1) when passing through the overflow building. After passing through the overflow building, the flow becomes super critical (FR>1) and gradually becomes normal again when in the downstream area. Specific energy produced in Ogee type overflow buildings also depends on the type of spill provided.
\end{abstract}

Keywords: Ogee Type Overflow, Flow Characteristics, Specific Energy 


\section{PENDAHULUAN}

Daerah aliran sungai merupakan daerah yang dibatasi oleh pemisah topografi yang merupakan daerah tangkapan air (catchment area). DAS mempunyai manfaat penting bagi kelangsungan hidup manusia, tumbuhan dan hewan sekitarnya yang berfungsi menerima menampung dan mengalirkan air. Tetapi karena bertambahnya jumlah penduduk maka kondisi sumber daya hutan, tanah dan air di DAS menurun. Saluran terbuka merupakan saluran dimana air mengalir dengan muka air bebas.Salah satu bangunan pelengkap yang dimiliki oleh saluran terbuka adalah bangunan pelimpah yang berfungsi menjaga saluran dari bahaya pelimpahan.

Pelimpah (Spillway) merupakan salah satu bangunan pelengkap dari bendungan yang berfungsi sebagai pengaman terhadap bahaya air banjir yang melimpas diatas bendungan (overtopping). Selain itu, bangunan pelimpah juga berfungsi agar debit hujan rancangan yang terjadi cepat mengalir sehingga debit air tidak sempat meluas.

Karakteristik aliran yang melewati bangunan pelimpah akan tergantung kepada bentuk dan sifat pelimpah itu sendiri. Untuk kepentingan bangunan air seperti bendungan dan bangunan air lainnya maka perihal karakteristik aliran sangatlah penting untuk menentukan bangunan yang akan dipilih sesuai kebutuhannya. Pengkajian tentang hal ini dapat dilakukan melalui suatu penelitian terhadap aliran pada saluran terbuka berukuran kecil yang melewati pelimpah dengan model bangunan pelimpah type ogee.

Dalam penelitian ini dilakukan pada jenis bangunan pelimpah type ogee dengan bentuk perbandingan yang berbeda - beda dengan memperhatikan karakteristik aliran yang terjadi di bagian hulu dan hilir bangunan pelimpah type ogee pada saluran terbuka. Percobaan ini dilakukan di laboratorium Hidroulika dengan menggunakan flum pada debit konstan dan debit yang bervariasi.

\section{Rumusan Masalah}

Sebagaimana latar belakang tersebut dapat dirumuskan masalah sebagai berikut:

1. Bagaimana karakteristik aliran pada bangunan pelimpah tipe ogee ? 
2. Bagaimana pola aliran setalah pelepasanarusdaribendunganatautangg melewati bangunan pelimpah tipe ulkedaerahhilir.Spillwaymeloloskan ogee?

banjir,

3. Bagaimana energi spesifik pada sehinggaairtidakmelampauitanggulata bangunan pelimpah tipe ogee ? utubuhbendungan.Pada

\section{Tujuan Penelitian}

Adapun tujuan dari penelitian ini adalah:

prinsipnyafungsipelimpah

untukmenghindarikerusakanbendunga n.

1. Mengetahui kerakteristik aliran yang terjadi pada bangunan pelimpah tipe ogee

\section{Pelimpah Tipe Ogee}

Mercu ogee berbentuk tirai luapan bawah dari bendung ambang

2. Mengetahui pola aliran yang terjadi pada bangunan pelimpah tipe ogee

3. Mengetahui energi spesifik pada bangunan pelimpah tipe ogee

\section{TINJAUAN PUSTAKA}

\section{Bendung}

Bendung adalah pembatas yang dibangun melintasi sungai yang dibangun untuk mengubah karakteristik aliran sungai. Dalam banyak kasus, bendung merupakan sebuah konstruksi yang jauh lebih kecil dari bendungan yang menyebabkan air menggenang membentuk kolam tetapi mampu melewati bagian atas bendung.

\section{Bangunan Pelimpah}

Pelimpah (spillway) adalah suatustrukturyangdigunakanuntukmen gontrol tajam aerasi. Oleh karena itu mercu ini tidak akan memberikan tekanan subatmosfir pada permukaan mercu sewaktu bendung mengalirkan air pada debit rencana. (Salomo Simanjuntak: 2009).
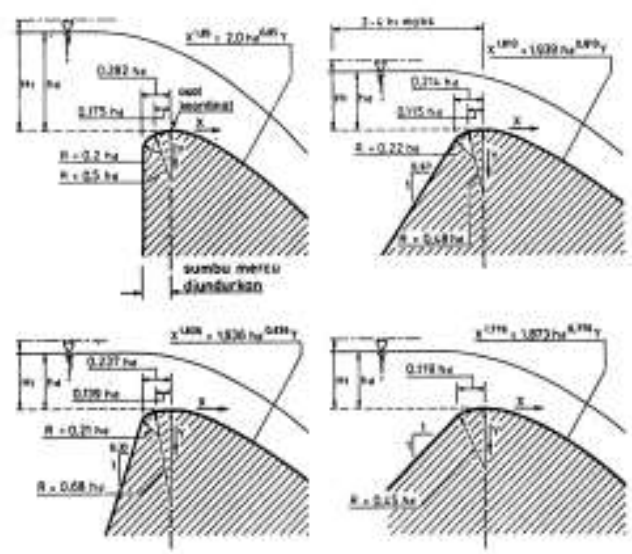

Gambar 1. Bentuk-bentuk Pelimpah Tipe Ogee Persamaan antara tinggi energi dan debit untuk pelimpah Ogee adalah: 
$\mathrm{Q}=\frac{\text { volume }(\mathrm{v})}{\text { waktu rata-rata (tr) }}$

$\mathrm{Cd}=\frac{\mathrm{Q}}{\frac{2}{3} \cdot \mathrm{b} \cdot \sqrt{2 \cdot \mathrm{g} \cdot \mathrm{H}^{1,5}}}$

\section{Energi Spesifik}

Energi spesifik adalah tinggi tenaga pada sembarang tampang diukur dari dasar saluran.

Besarnya energi spesifik dapat dirumuskan sebagai berikut (Ven Te Chow, 1959 dalam Robert,J.K., 2002) : $\mathrm{E}=\frac{v^{2}}{2 g}$

\section{METODE PENELITIAN}

Metode penelitian yang digunakan dalam penelitian ini adalah metode penelitian eksperimen laboratorium yang meliputi pengamatan atau pengukuran terhadap parameter aliran pada saluran terbuka yang menggunakan bangunan pelimpah tipe ogee dengan memperhitungkan parameter hidrolis.

Penelitian dilaksanakan di Laboratorium Hidraulika Fakultas Teknik Universitas Muslim Indonesia Makassar. Penelitian ini dilakukan selama 3 bulan, dimana bulan pertama dan kedua merupakan kajian literatur mengenai karakteristik aliran pada saluran terbuka dan melakukan desain alat kemudian dilanjutkan dengan running, selanjutnya pada bulan ketiga melakukan pengambilan dan analisis data.

Secara umum, alat dan bahan yang digunakan dalam menunjang penelitian ini terdiri dari open flume, pelimpah, stopwatch, kamera, pompa air, dan mistar ukur.

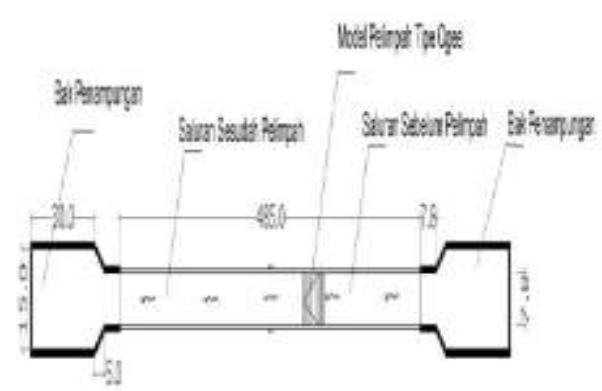

Gambar 2. Denah Alat Penelitian

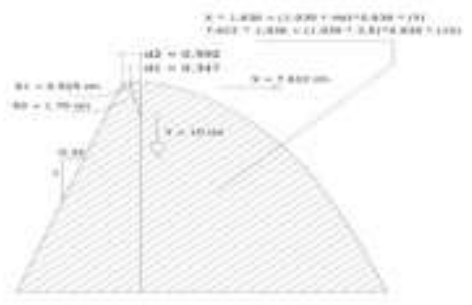

Gambar 3. Pelimpah Tipe Ogee Dimensi 1:1

Gambar 4. Pelimpah Tipe Ogee Vertikal 


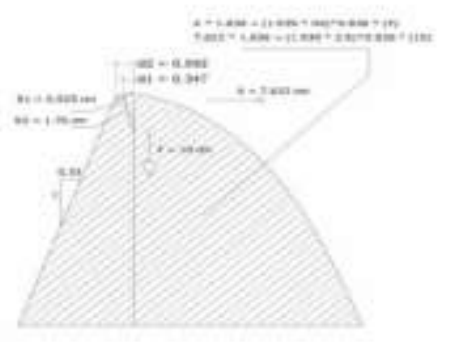

Gambar 5. Pelimpah Tipe Ogee 1:3
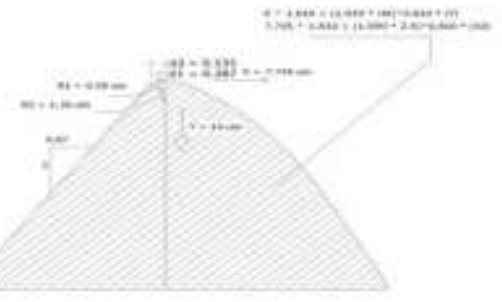

Gambar 6.Pelimpah Tipe Ogee 2:3

\section{HASIL DAN PEMBAHASAN}

\section{Analisis Koefisien Debit (Cd)}

Cd merupakan koefisien debit pada pelimpah dan besarnya $\mathrm{Cd}$ rata-rata adalah 1,1115, sebagai contoh pelimpah tipe ogee 1:3 untuk $(\mathrm{H})=$ $0.035 \mathrm{~m}$, volume air $(\mathrm{v})=0.01 \mathrm{~m}^{3}$, dengan waktu pengaliran sebagai berikut : 6,59 det, 6,16 det, 6,00 det. Total waktu pengaliran $=18,75$ det.

Waktu aliran rata-rata $\operatorname{tr}=\frac{18,75}{3}=6,25$ det.

$$
\begin{aligned}
Q & =\frac{\text { volume }(\mathrm{v})}{\text { waktu rata-rata }(\text { tr })} \\
& =\frac{0.010 \mathrm{~m}^{3}}{6,25}
\end{aligned}
$$

$$
=0,0016 \mathrm{~m}^{3} / \mathrm{det}
$$

$$
\begin{aligned}
\mathrm{Cd} & =\frac{\mathrm{Q}}{\frac{2}{3} \cdot \mathrm{b} \cdot \sqrt{2 \cdot \mathrm{g} \cdot \mathrm{H}^{1,5}}} \\
& =\frac{0,0016}{\frac{2}{3} \cdot 0,078 \cdot \sqrt{2 \cdot 9,81} \cdot 0,035^{1,5}} \\
& =1,1875 .
\end{aligned}
$$

Perhitungan selanjutnya diselesaikan dengan cara yang sama dan hasilnya dirangkum dalam tabel 1

\begin{tabular}{|c|c|c|c|c|c|}
\hline 1 & 0,078 & & 0,041 & 0016 & \\
\hline 2 & 0,078 & 035 & & & 0677 \\
\hline 3 & 0,078 & 0,036 & 0,0 & 0,0015 & 0,9709 \\
\hline 4 & 0,0 & & & & \\
\hline 5 & 0,078 & 0,041 & 4,750 & & 1,1010 \\
\hline 6 & 0,07 & 12 & 7 & & \\
\hline 7 & 0,078 & 045 & 3,687 & & 2337 \\
\hline 8 & 0,078 & 15 & 3,5 & & 1,2669 \\
\hline 9 & 0,078 & 0,046 & 3,850 & & 1,1430 \\
\hline 0 & 0,078 & 0,047 & 3,657 & 0,0027 & 1,1652 \\
\hline \multicolumn{5}{|c|}{ Rata-rata Cd } & 1,1115 \\
\hline
\end{tabular}
dengan masing-masing volume 0,01 $\mathrm{m}^{3}$ :

Tabel 1. Perhitungan koefisien debit volume $0,01 \mathrm{~m}^{3}$

$$
\text { No } b(\mathrm{~m}) \quad \mathrm{h}(\mathrm{m}) \quad \sum \mathrm{t}(\mathrm{det}) \underset{\left(\mathrm{m}^{3} / \mathrm{det}\right)}{\mathrm{Q}} \quad \mathrm{Cd}
$$

Untuk Koefisien debit pelimpah tipe ogee 1:1 terdapat pada tabel 105

Untuk Koefisien debit pelimpah tipe

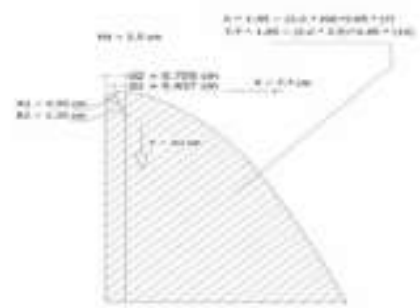

ogee 2:3 terdapat pada tabel 37 Untuk Koefisien debit pelimpah tipe ogee vertikalterdapat pada tabel 3 


\begin{tabular}{lccccc} 
Tinggi Muka Air dan Luas & 3 & 3,4 & 0,096 & 0,0075 \\
Penampang & 4 & 4,05 & 0,102 & 0,0080 \\
Dari hasil ketinggian air dapat dihitung & 5 & 4,8 & 0,114 & 0,0089 \\
\cline { 3 - 6 }
\end{tabular}
luas penampang pada tiap titik didaerah Hasil perhitungan luas penampang hulu, contoh untuk pelimpah ogee 1:3 pada daerah hilir pelimpah tipe ogee dimana $\mathrm{b}=0,078 \mathrm{~m} \mathrm{H}=0,154 \mathrm{~m}$, luas $1: 1$ terdapat pada tabel 106 penampang $\mathrm{A}=\mathrm{b} \times \mathrm{H}=0.078 \times 0,154$ Hasil perhitungan luas penampang $=0,0120 \mathrm{~m}^{2}$. pada daerah hilir pelimpah tipe ogee

Hasil perhitungan luas penampang pada daerah hilir, dimana $b=0,078$ m $\mathrm{H}=0,081 \mathrm{~m}$, luas penampang $\mathrm{A}=\mathrm{b}$ $\mathrm{x} \quad \mathrm{H}=0,0063 \mathrm{~m}^{2}$. Perhitungan selanjutnya dihitung dengan cara yang sama.

2:3 terdapat pada tabel 38

Hasil perhitungan luas penampang pada daerah hilir pelimpah tipe ogee vertikal terdapat pada tabel 4

\section{Kecepatan Aliran, Bilangan Froude,} dan Energi Spesifik

Tabel 2. Hasil perhitungan luas penampang pada daerah hilir dengan debit $0,0015 \mathrm{~m}^{3} /$ det, $0,002 \mathrm{~m}^{3} /$ det dan $0,0025 \mathrm{~m}^{3} /$ det.

\begin{tabular}{cccccc}
\hline No & $\begin{array}{c}\mathrm{Q} \\
(\mathrm{m} 3 / \mathrm{det})\end{array}$ & $\begin{array}{c}\text { Jarak } \\
(\mathrm{m})\end{array}$ & $\mathrm{h}(\mathrm{m})$ & $\begin{array}{c}\mathrm{b} \\
(\mathrm{m})\end{array}$ & $\mathrm{A}\left(\mathrm{m}^{2}\right)$ \\
\hline 1 & & 2 & 0,081 & & 0,0063 \\
2 & & 2,75 & 0,083 & & 0,0065 \\
3 & 0,0015 & 3,4 & 0,085 & 0,078 & 0,0066 \\
4 & & 4,05 & 0,091 & & 0,0071 \\
5 & & 4,8 & 0,097 & & 0,0076 \\
1 & & 2 & 0,086 & & 0,0067 \\
2 & & 2,75 & 0,088 & & 0,0069 \\
3 & 0,0020 & 3,4 & 0,09 & 0,078 & 0,0070 \\
4 & & 4,05 & 0,093 & & 0,0073 \\
5 & & 4,8 & 0,103 & & 0,0080 \\
1 & & 2 & 0,094 & 0,078 & 0,0073 \\
2 & 0,0025 & 2,75 & 0,095 & & 0,0074 \\
\hline
\end{tabular}

Hasil perhitungan kecepatan aliran pada daerah hulu sebagai contoh pelimpah tipe ogee 1:3 dapat dilihat pada tabel sebagai berikut dengan debit $0,0015 \mathrm{~m}^{3} /$ det, $0,0020 \mathrm{~m}^{3} /$ det, dan 0,0025 $\mathrm{m}^{3} /$ det. Kecepatan didaerah hulu dilakukan lima kali percobaan tiap jarak, pada debit 0,0015 $\mathrm{m}^{3} /$ det dengan waktu pengaliran 5,98 detik, 5,76 detik, 5,59 detik, 5,93 detik, dan 5,59 detik. Total waktu pengaliran $=$ 28,85 detik.

Waktu aliran rata-rata:

$$
\begin{aligned}
\operatorname{tr} & =\frac{28,85}{5}=5,770 \text { detik. } \\
\mathrm{V} & =\frac{\text { jarak }}{\text { waktu rata-rata (tr) }}=\frac{0,80}{5,770} \\
& =0,1386 \mathrm{~m} / \mathrm{det} .
\end{aligned}
$$




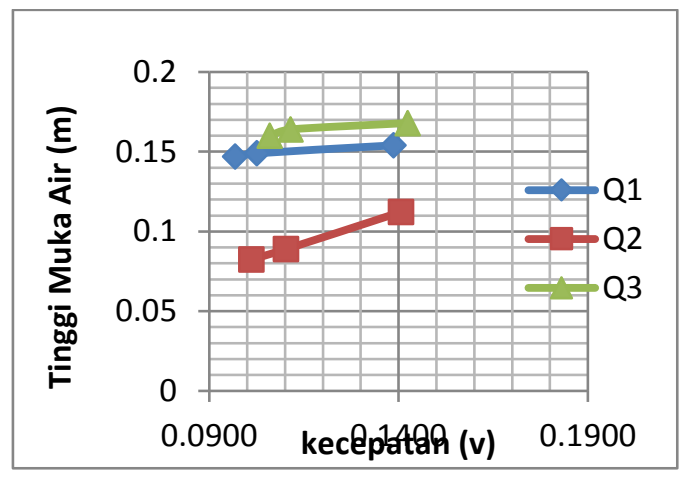

Gambar7. Hubungan antara kecepatan dan tinggi muka air pada daerah hulu

Hasil perhitungan bilangan froude pada debit $0,0015 \mathrm{~m}^{3} /$ det, $0,0020 \mathrm{~m}^{3} /$ det, dan $0,0025 \mathrm{~m}^{3} /$ det di daerah hulu dapat dilihat pada tabel berikut, pada debit $0,0015 \mathrm{~m}^{3} /$ det $\mathrm{V}=$ $0,1364 \mathrm{~m} /$ det, $\mathrm{g}=9,81 \mathrm{~m}^{2} / \mathrm{det}, \mathrm{h}=0,15$ $m$ dan dijabarkan sebagai berikut:

$\operatorname{Fr}=\frac{0,1364}{\sqrt{9,81.0,15}}=0,1128$.

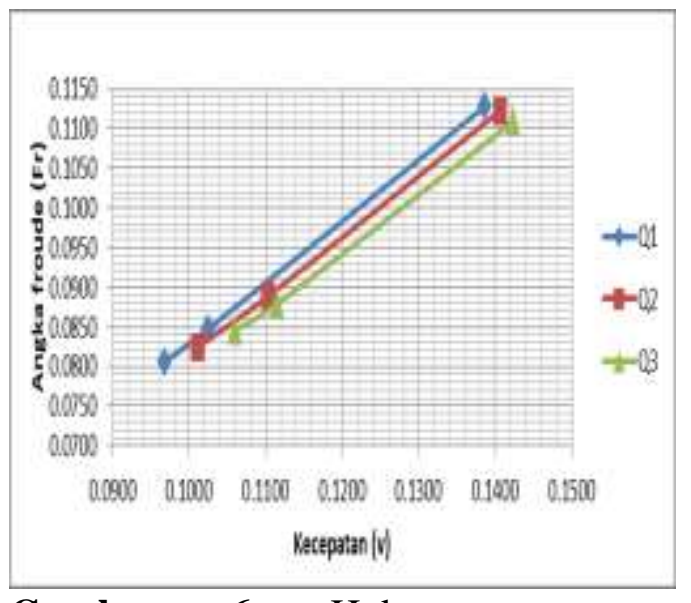

Gambar 6. Hubungan antara kecepatan dan bilangan froude pada bagian hulu

Hasil perhitungan energi spesifik pada debit $0,0015 \mathrm{~m}^{3} /$ det, $0,0020 \mathrm{~m}^{3} /$ det, dan $0,0025 \mathrm{~m}^{3} /$ det di daerah hulu dapat dilihat pada tabel berikut.

Es $=0,15+\left(\frac{0,1364^{2}}{2 \cdot 9,81}\right)=0,1550 \mathrm{~m}$.

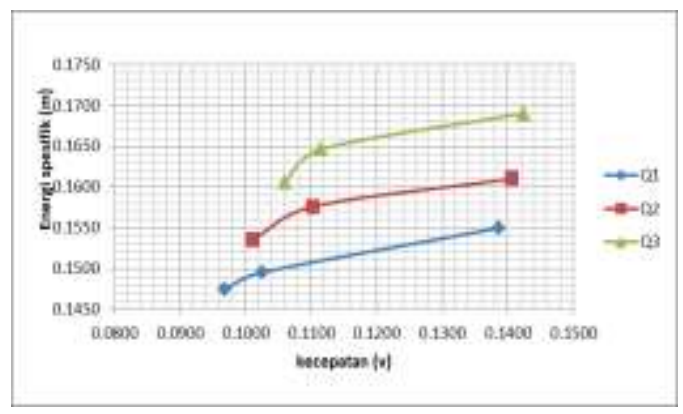

Gambar 7.Hubungan antara kecepatan dan energi spesifik pada daerah hulu.

Perhitungan kecepatan pada bangunan dengan debit $0,0015 \mathrm{~m}^{3} / \mathrm{det}$, $0,0020 \mathrm{~m}^{3} / \mathrm{det}$, dan $0,0025 \mathrm{~m}^{3} / \mathrm{det}$ dirangkum pada tabel 16, dimana $\mathrm{Q}$ $=0,0015 \mathrm{~m}^{3} / \mathrm{det}, \mathrm{b}=0,078 \mathrm{~m}, \mathrm{~g}=9,81$ $\mathrm{m}^{2} /$ det dan dijabarkan sebagai berikut: $\mathrm{q}=\frac{\mathrm{Q}}{\mathrm{b}}=\frac{0,0015}{0,078}=0,0192 \mathrm{~m}^{3} / \mathrm{det} / \mathrm{m}$ $\mathrm{h}_{\mathrm{c}}=\sqrt[3]{\frac{\mathrm{q}^{2}}{\mathrm{~g}}}=\sqrt[3]{\frac{0,0192^{2}}{9,81}}=0,033 \mathrm{~m}$ $\mathrm{Vc}=\sqrt{\mathrm{g} \cdot \mathrm{yc}}=\sqrt{9,81 \times 0,033}=0,5733$ $\mathrm{m} / \mathrm{det}$

Perhitungan bilangan froude pada bangunan pada debit 0,0015 $\mathrm{m} 3 /$ det, $0,0020 \mathrm{~m} 3 /$ det, dan 0,0025 m3/det dirangkum pada tabel 23, dimana $\mathrm{Q}=0,0015 \mathrm{~m} 3 / \mathrm{det}, \mathrm{b}=$ $0,078 \mathrm{~m}, \quad \mathrm{~g}=9,81 \mathrm{~m} 2 /$ det dan dijabarkan sebagai berikut:

$\mathrm{Fr}=\frac{\mathrm{V}}{\sqrt{\mathrm{g} \cdot \Delta \mathrm{y}}}=\frac{0,5733}{\sqrt{9,81 \cdot 0,033}}=1$ 
Perhitungan energi spesifik pada bangunan, dimana $\mathrm{Q}=0,0015$ $\mathrm{m}^{3} /$ det, $\mathrm{yc}=0,0335 \mathrm{~m}, \mathrm{Vc}=0,5735$ $\mathrm{m} / \mathrm{det}, \mathrm{g}=9,81$ dan dijabarkan sebagai berikut :

Es $=0,0335+\left(\frac{0,5735^{2}}{2 \cdot 9,81}\right)=0,0503 \mathrm{~m}$

Perhitungan selanjutnya dihitung dengan cara yang sama.

Perhitungan kecepatan pada daerah setelah bangunan dengan debit $0,0015 \mathrm{~m}^{3} /$ det, $0,0020 \mathrm{~m}^{3} /$ det, dan $0,0025 \mathrm{~m}^{3} /$ det dirangkum pada tabel 17,18, dan 19 dimana $\mathrm{Q}=0,0015$ $\mathrm{m}^{3} /$ det, $\mathrm{b}=0,078 \mathrm{~m}, \mathrm{~g}=9,81 \mathrm{~m}^{2} /$ det, y2 =0,114 ( Tinggi muka air sebelum melewati bangunan) dan dijabarkan sebagai berikut:

$\Delta \mathrm{y}=\mathrm{y} 2-\mathrm{y} 1=0,114-0,043=0,0540 \mathrm{~m}$ $\mathrm{V}=\sqrt{2 \cdot \mathrm{g} \cdot \Delta \mathrm{y}}=\sqrt{2 \cdot 9,81 \cdot 0,0540}=$ $1,0293 \mathrm{~m} / \mathrm{det}$

Perhitungan bilangan froude pada daerah setelah bangunan pelimpah pada debit $0,0015 \mathrm{~m}^{3} /$ det, 0,0020 $\mathrm{m}^{3} /$ det, dan $0,0025 \mathrm{~m}^{3} /$ det dirangkum pada tabel 24, dimana $\mathrm{Q}=0,0015$ $\mathrm{m}^{3} /$ det, $\mathrm{b}=0,078 \mathrm{~m}, \mathrm{~g}=9,81 \mathrm{~m}^{2} / \mathrm{det} \mathrm{V}$ $=0,8635 \mathrm{~m} / \mathrm{det}, \Delta \mathrm{y}=0,0540 \mathrm{~m}$ dan dijabarkan sebagai berikut :

$\mathrm{Fr}=\frac{\mathrm{V}}{\sqrt{\mathrm{g} \cdot \Delta \mathrm{y}}}=\frac{0,8635}{\sqrt{9,81 \cdot 0,0540}}=1,53295$
Perhitungan energi spesifik pada daerah setelah bangunan pada debit $0,0015 \mathrm{~m}^{3} /$ det, $0,0020 \mathrm{~m}^{3} /$ det, $0,0025 \mathrm{~m}^{3} /$ det. Pada debit 0,0015 $\mathrm{m}^{3} /$ det, dimana $\Delta \mathrm{y}=0,0380 \mathrm{~m}, \mathrm{~V}=$ $0,8635 \mathrm{~m} / \mathrm{det}, \mathrm{g}=9,81$ dan dijabarkan sebagai berikut:

Es $=0,0380+\left(\frac{0,8635^{2}}{2 \cdot 9,81}\right)=0,076 \mathrm{~m}$

Perhitungan selanjutnya dihitung dengan cara yang sama dan dirangkum pada tabel.

Hasil perhitungan kecepatan pada daerah hilir pada debit 0,0015 $\mathrm{m}^{3} /$ det, $0,0020 \mathrm{~m}^{3} /$ det, $0,0025 \mathrm{~m}^{3} /$ det, dicari menggunakan current meter dan dirangkum pada tabel.

Hasil perhitungan bilangan froude pada daerah hilir pada debit $0,0015 \mathrm{~m}^{3} / \mathrm{det}, 0,0020 \mathrm{~m}^{3} / \mathrm{det}, 0,0025$ $\mathrm{m}^{3} /$ det, pada debit $0,0015 \mathrm{~m}^{3} /$ det dimana $V=0,30 \mathrm{~m}, \mathrm{~g}=9,81, \mathrm{y}=0,081$ $\mathrm{m}$ dan dijabarkan sebagai berikut :

$\mathrm{Fr}=\frac{\mathrm{V}}{\sqrt{\mathrm{g} \cdot \mathrm{y}}}=\frac{0,30}{\sqrt{9,81 \cdot 0,081}}=0,3365$

Perhitungan selanjutnya dikerjakan dengan cara yang sama dan dirangkum pada tabel.

Apabila kecepatannya besar maka energy spesifiknya akan tinggi. Dapat dilihat bahwa energy spesifik 
yang paling tinggi terdapat pada debit (Q3=0.0025 m/det).

Hasil perhitungan energi spesifik pada daerah hilir pada debit $0,0015 \mathrm{~m}^{3} /$ det, $0,0020 \mathrm{~m}^{3} /$ det, 0,0025 $\mathrm{m}^{3} /$ det, pada debit $0,0015 \mathrm{~m}^{3} /$ det dimana $\mathrm{h}=0,081 \mathrm{~m}, \mathrm{~V}=0,30 \mathrm{~m} / \mathrm{det}, \mathrm{g}$ $=9,81$ dan dijabarkan sebagai berikut:

Es $=0,081+\left(\frac{0,30^{2}}{2.9,81}\right)=0,0856 \mathrm{~m}$

Perhitungan selanjutnya diselesaikan dengan cara yang sama dan hasilnya dirangkum dalam tabel 3.

Tabel 3. Hasil perhitungan kecepatan aliran, bilangan froude, dan energi spesifik pada daerah hilir dengan debit $0,0015 \mathrm{~m}^{3} /$ det, $0,0020 \mathrm{~m}^{3} /$ det, 0,0025 $\mathrm{m}^{3} /$ det

\begin{tabular}{|c|c|c|c|c|}
\hline No & $\underset{(\mathrm{m} 3 / \mathrm{det})}{\mathrm{Q}}$ & $\mathrm{h}(\mathrm{m}$ & $\begin{array}{c}\mathrm{V} \\
(\mathrm{m} / \mathrm{det})\end{array}$ & $\mathrm{Fr}$ \\
\hline 1 & & 0,08 & 0,30 & $0,3360,085$ \\
\hline 2 & & 0,08 & 0,30 & $0,3320,087$ \\
\hline 3 & 0,0015 & 0,08 & 0,30 & $0,3220,092$ \\
\hline 4 & & 0,09 & 0,20 & $0,2060,098$ \\
\hline 5 & & 0,11 & 0,20 & $0,1900,115$ \\
\hline 1 & & 0,08 & 0,30 & $0,3280,089$ \\
\hline 2 & & 0,08 & 0,30 & $0,3220,092$ \\
\hline 3 & 0,002 & 0,09 & 0,30 & $0,3140,097$ \\
\hline 4 & & 0,10 & 0,20 & $0,2000,103$ \\
\hline 5 & & 0,11 & 0,20 & $0,1850,121$ \\
\hline 1 & & 0,09 & 0,40 & $0,4100,105$ \\
\hline 2 & & 0,10 & 0,40 & $0,4010,109$ \\
\hline 3 & 0,0025 & 0,10 & 0,40 & $0,3990,110$ \\
\hline 4 & & 0,11 & 0,30 & $0,2860,116$ \\
\hline 5 & & 0,12 & 0,30 & $0,2750,125$ \\
\hline
\end{tabular}

\section{Kehilangan Energi}

Kehilangan energi spesifik pada daerah hulu dan hilir pada debit 0,0015 $\mathrm{m}^{3} /$ det dititik tinjauan dengan jarak 0,65 $\mathrm{m}$ sebelum pelimpah dan jarak $2.00 \mathrm{~m}$ pada daerah hilir adalah sebagai berikut :

$\Delta \mathrm{E}=0,1475-0,0856=0,0619 \mathrm{~m}$

Kehilangan energi spesifik pada daerah hulu dan hilir pada debit 0,002 $\mathrm{m}^{3} /$ det dititik tinjauan dengan jarak 0,64 m sebelum pelimpah dan jarak $2.00 \mathrm{~m}$ pada daerah hilir adalah sebagai berikut :

$\Delta \mathrm{E}=0,1535-0,0906=0,0629 \mathrm{~m}$

Kehilangan energi spesifik pada daerah hulu dan hilir pada debit 0,0025 $\mathrm{m}^{3} /$ det dititik tinjauan dengan jarak 0,64 $\mathrm{m}$ sebelum pelimpah dan jarak $2.00 \mathrm{~m}$ pada daerah hilir adalah sebagai berikut :

$\Delta \mathrm{E}=0,1606-0,1022=0,0584 \mathrm{~m}$

Kehilangan energi spesifik pada daerah setelah bangunan sebagai contoh pada debit 0,0015 $\mathrm{m}^{3} /$ det dengan $\mathrm{y} 1=0,045 \mathrm{~m}, \mathrm{y} 2=0,081 \mathrm{~m}$ dihitung dan dijabarkan sbb :

$\Delta \mathrm{y}=\mathrm{y} 2-\mathrm{y} 1=0,081-0,043$

$$
=0,0380 \mathrm{~m} \text {. }
$$

$\Delta \mathrm{E}=\frac{(\mathrm{y} 2-\mathrm{y} 1)^{3}}{4 \mathrm{xy} 2 \mathrm{xy} 1}=\frac{0.0380}{4 \mathrm{x} 0,1 \times 0,045}$ 


$$
=0.002170 \mathrm{~m} \text {. }
$$

\section{Debit}

Dari penelitian ini digunakan 3 variasi debit yaitu $0,0015 \mathrm{~m}^{3} / \mathrm{det}$, $0,0020 \mathrm{~m}^{3} /$ det, $0,0025 \mathrm{~m}^{3} /$ det.

\section{Kecepatan Aliran}

Dari hasil perhitungan pada tabel diketahui bahwa semakin tinggi muka air maka semakin besar kecepatan yang terjadi.

Dari hasil perhitungan pada tabel 18, 19 dan 20 diketahui bahwa semakin tinggi muka air maka semakin rendah kecepatan yang terjadi.

Dari hasil perhitungan pada tabel 21 dengan menggunakan current meter dan dari hasil perhitungan kecepatan paling besar terjadi pada saat setelah air melewati bangunan pelimpah.

\section{Bilangan Froude}

Dari hasil perhitungan diperoleh bilangan Froude yang cukup bervariasi dikarenakan pengambilan data dilakukan pada jarak tertentu tiap titiknya.

\section{Energi Spesifik}

Dari hasil perhitungan energi spesifik pada daerah hulu diketahui bahwa semakin besar kecepatan maka semakin besar pula energi spesifik yang terjadi. Pada daerah hilir dapat diketahui bahwa semakin besar kecepatan maka semakin kecil energi yang terjadi.

\section{Kehilangan Energi}

Dari hasil perhitungan kehilangan energi dapat dilihat pada daerah hulu dan hilir dimana semakin tinggi debit maka kehilangan energi semakin rendah.

\section{PENUTUP}

\section{Kesimpulan}

Adapun kesimpulan pada penelitian pengaruh bangunan pelimpah tipe ogee terhadap karasteristik aliran pada saluran terbuka adalah:

1) Aliran air dapat mengalami perubahan ketinggian karena adanyabangunan pelimpah dan berpengaruh pada karakteristik alirannya.Dimana semakin tinggi muka air maka semakin besarkecepatan yangterjadi.

2) Pola aliran pada daerah hulu merupakan aliran sub kritis $(\mathrm{FR}<1)$ kemudian menjadi kritis (FR = 1) pada saat melewati bangunanpelimpah. Setelah melewati bangunasuper kritis (FR > 
1) dan berangsur-angsur menjadi normal kembali padasaat berada di daerah hilir.

3) Energy spesifik yang terjadi pada tiap-tiap pelimpah bervariasi tergantung dari jenis pelimpah tipe ogee yang digunakan.

\section{Saran}

Disadari bahwa penelitian ini jauh dari kesempurnaan, sehingga penelitian ini masih perlu dikaji untuk beberapa kondisi berikut.

1) Pengukuran kecepatan aliran dan tinggi muka air agar dilakukan dengan teliti lagi agar mendapatkan hasil yang lebih akurat.

2) Untuk penyempurnaan dan pengembangan,penelitianselanjutny a disarankan untuk memakai kolam olakan dan menggunakan saluran yang lebihlebar lagi.

\section{DAFTAR PUSTAKA}

I Gst. Lanang Made Parwita. 2017. Jurnal Kajian Teknis Efektivitas Pengukuran Debit melalui Peilschale Bendung Tirtayasa (Volume 17 No. 1). Fakultas Teknik, Politeknik Negeri Bali.

Muttafaq, Warid dkk. Jurnal Perencanaan Bangunan Pelimpah Samping (Side Channel Spillway) Bendungan
Budong-Budong Kabupaten

Mamuju Tengah Provinsi

Sulawesi Barat. Fakultas

Teknik Universitas Brawijaya, Malang.

Norhadi, Ahmad dkk. 2015. Jurnal Studi Debit Aliran pada Sungai Antasan Kelurahan Sungai Andai Banjarmasin Utara (Volume 7 No. 1). Fakultas Teknik, Politeknik Negeri Banjarmasin.

Risman dan Warsiti.2013. Jurnal Kajian Aliran Melalui Pelimpah Ambang Lebar dan Pelimpah Ambang Tipis (Volume 18 No. 1). Fakultas Teknik Politeknik Negeri Semarang.

Soekarno, Indratmo dan Heruyoko. 2009. Jurnal Kajian Hubungan Antara Debit Berubah dengan Tinggi Muka Air dan Kecepatan Aliran (Volume 16 No. 1). Fakultas Teknik Sipil dan Lingkungan, Institut Teknologi bandung.

Sumirman, Edi dan Umboro Lasminto. 2013. Jurnal Studi Perbandingan Aliran Alat Ukur Debit Ambang Tipis Penampang Segi Tiga dengan Penampang Majemuk.Fakultas Teknik ITS, Surabaya.

Vicky, R.M. 2013. Jurnal Perencanaan Bendung untuk Daerah Irigasi Sulu(Volume 1 No. 7). Fakultas 
Teknik Universitas Sam Kodoatie, Robert J. 2002. Hidrolika Ratulangi, Manado. Terapan Edisi Revisi. Penerbit Andi, Yogyakarta.

Yudhit, P.P. 2014. Jurnal Perubahan Peningkatan Kapasitas

Spillway Mercu Ogee terhadap Mercu Deret Sinusoida.Fakultas Teknik, Universitas Jember.

Zusfrisal, Mochammad dkk.2016. Jurnal Studi Perencanaan Bendung Daerah Irigasi Balansai Kabupaten Seram Bagian Timur Provinsi Maluku. Fakultas Teknik Universitas Brawijaya.

Canonica, Lucio. 2013. Memahami Hidraulika Edisi Revisi. CV Angkasa, Bandung.

Chow, VT. 1985. Terjemahan Suyatman, Sugiharto, dan Rosalina. Hidrolika Saluran Terbuka. Penerbit Erlangga, Jakarta.

Direktur Jenderal Pengairan. 1986. Kriteria Perencanaan. Direktorat Jenderal Pengairan, Jakarta.

Ernandi, Rhidho. 2012. Aliran Fluida. 17 Mei 2012.Online dari http://Ridho-Ernandi/aliranfluida.html.Diakses pada tanggal 9 Maret 2018.

Gandakoesoema. 1983.

Hidrolika. Penerbit Sumur Bandung, Bandung.

Simanjuntak, Salomo. 2009. Analisa Mercu Bendung Daerah Irigasi Namurambe. Laporan Penelitian, Medan: Lembaga Penelitian Universitas HKBP Nommensen.

SNI 8137. 2015. Pengukuran Debit pada Saluran Terbuka Menggunakan Bangunan Ukur Tipe Pelimpah Atas. Badan Standar Nasional, Jakarta.

Triatmodjo, Bambang. 1993. Hidrolika II. Beta Offset, Yogyakarta.

Farisi, Hafidh dkk. 2014. Jurnal Kajian Perencanaan Bangunan Pelmpah Bendungan Cibatarua Kabupaten Garut. Fakultas Teknik Universitas Brawijaya.

Bachtiar Ahmad Saifi, Heri Suprijanto, M. Janu Ismoyo.2014. kajian hidraulika bangunan pelimpah samping (side channel spillway) Bendungan sukamahi dengan uji model 1:30. Fakultas Teknik Universitas Brawijaya.

Risman, Warsiti, Mawardi, Martono, Lilik Satriyadi.2015. kajian perilaku aliran melalui alat ukur debit mercu bulat terhadap tinggi muka air. Staf pengajar jurusan teknik sipil Politeknik Negeri Semarang. 
Volume 12 Nomor 2, Agustus 2019

Dani Elisa Victory, Siswanto, Trimaijon.2016. Kajian Lebar

Bangunan Pelimpah Tipe

Lengkung Terhadap Elevasi

Muka Banjir (Studi Kasus

Waduk Tenayan). Fakultas

Teknik Universitas Riau

Sarwono, Kirno.2014. Penyempurnaan

Desain Bangunan Pelimpah

Cileuweung dengan uji model hidraulika fisik.Peneliti Madya

Bidang Hidraulika dan

Bangunan Air Balai Sungai.

Rahmah Dara Lufira, Suwanto

Marsudi.2015. Analisa Uji

Model Fisik Pelimpah

Bendungan Sukahurip di

Kabupaten Pangandaran Jawa

Barat.Fakultas Teknik

Universitas Brawijaya. 